

\title{
ANÁLISE DA UTILIZAÇÃO DAS TECNOLOGIAS DA INDÚSTRIA 4.0 NOS MODELOS DE NEGÓCIOS DE PMES DO SETOR METALMECÂNICO
}

\author{
ANALYSIS OF THE USE OF INDUSTRY 4.0 TECHNOLOGIES IN THE SMES BUSINESS \\ MODEL IN THE METAL-MECHANIC SECTOR
}

\author{
Gustavo Fucks \\ iD Laura Visintainer Lerman ${ }^{2}$ \\ ID Guilherme Brittes Benitez ${ }^{3}$ \\ D Mateus José do Rego Ferreira Lima ${ }^{4}$ \\ ID Alejandro Germán Frank ${ }^{5}$
}

${ }^{1}$ Bacharel em Engenharia de Produção Universidade Federal do Rio Grande do Sul - UFRGS. Porto Alegre, Rio Grande do Sul - Brasil. gustavof988@gmail.com

${ }^{2} \mathrm{MSc}$ em Engenharia de Produção Universidade Federal do Rio Grande do Sul - UFRGS. Porto Alegre, Rio Grande do Sul - Brasil. laura.lerman@ufrgs.br

${ }^{3}$ Doutor em Engenharia de Produção Universidade Federal do Rio Grande do Sul - UFRGS. Porto Alegre, Rio Grande do Sul - Brasil. guilherme.benitez@ufrgs.br

${ }^{4} \mathrm{MSc}$ em Engenharia de Produção The Ohio State University - $\mathrm{OH}$. Columbus - Estados Unidos. doregoferreiralima.1@buckeyemail.osu.edu

${ }^{5}$ Doutor em Engenharia de Produção Universidade Federal do Rio Grande do Sul - UFRGS. Porto Alegre, Rio Grande do Sul - Brasil. frank@producao.ufrgs.br

Recebido em: 21 mar. 2020

Aprovado em: 06 ago. 2020
Resumo: Este artigo explora os conceitos e tecnologias da Indústria 4.0 ao analisar o modelo de negócios de empresas de pequeno e médio porte do setor metalmecânico brasileiro. O objetivo é identificar os principais problemas associados a modelo de negócios nas empresas do setor metalmecânico e apontar como as tecnologias da Indústria 4.0 possam auxiliar na resolução dos problemas. Entre os passos metodológicos, há um questionário aplicado em indústrias do setor metalmecânico que aborda a adoção de tecnologias 4.0 para a transição de automação para digitalização. Como resultado, a elaboração de um framework que sintetiza o desenvolvimento tecnológico das empresas e direciona as tecnologias 4.0 que devem ser priorizadas para transpor as dificuldades encontradas nos modelos de negócios. O estudo apontou que tecnologias voltadas para digitalização e integração de processos tendem a oferecer maiores benefícios ao setor e devem ser priorizadas para o desenvolvimento das PMEs.

Palavras-chave: Indústria 4.0. Modelos de negócios. PMEs. Setor metalmecânico.

Abstract: This article explores the concepts and technologies of Industry 4.0 by analyzing the business model of small and medium size companies in the Brazilian metalworking sector. The objective is to identify the main problems associated with the business model in companies of the metal-mechanic sector and to point out how the technologies of Industry 4.0 could help in solving the problems. Among the methodological there is a questionnaire applied in metal-mechanic industries which addresses the adoption of 4.0 technologies for the transition from automation to digitalization. As a result, a framework that synthesizes the technological development of companies and directs 4.0 technologies that must be prioritized to overcome the difficulties encountered in business models. The study pointed out that technologies focused on digitization and process integration tend to offer greater benefits to the sector and should be prioritized for the development of SMEs.

Keywords: Industry 4.0. Business model. SMEs. Metal-mechanic sector. 


\section{Introdução}

A indústria passou por marcos que revolucionaram a forma de desenvolver peças e produtos ao longo da história. Esses marcos são conhecidos como as revoluções industriais. Inicialmente, no século XVIII, o advento da energia proveniente do carvão tornou possível a primeira revolução. Em 1870, a descoberta de novas fontes de energia, como a elétrica, bem como a organização do trabalho, proporcionou a segunda revolução. Já nos anos 1970, os chips, a Internet e a automação foram a base da terceira revolução (Hermann et al., 2016). Atualmente, a digitalização dos processos, por meio da Internet das Coisas (IOT) e dos Sistemas Ciber-Físicos (CPS), vem transformando a forma de interação entre homens e máquinas, além da dinâmica nas fábricas e de aspectos do nosso cotidiano (Jeschke et al., 2017). Essa transformação é conhecida atualmente como Indústria 4.0 (Dalenogare et al., 2018). Os conceitos de digitalização de operações e parceria em toda cadeia de valor já estão mais consolidados em empresas de grande porte em países desenvolvidos, como Alemanha e Japão, e vêm resultando em ganhos de produtividade, diminuição de custos e garantia de qualidade (Kagermann et al., 2013). Entretanto, a indústria chinesa é a que possui a maior expectativa de crescimento devido à alta flexibilidade e abertura a mudanças digitais (PWC, 2016). Segundo a PWC (2016), a estimativa é de que a indústria global investirá cerca de US\$ 907 bilhões por ano até 2020 em tecnologias digitais (como sensores ou dispositivos de conectividade), softwares (de programação ou modelagem) e aplicações (sistemas de execução de manufatura, por exemplo). Por outro lado, países emergentes, como o Brasil, representam uma fatia muito pequena desses investimentos e necessitam de incentivos governamentais para não ficarem ainda mais em desvantagem (Reynolds \& Uygun, 2018). Empresas de países emergentes não possuem o mesmo poder de capital que multinacionais e que grandes empresas de países desenvolvidos contam para investir nas ferramentas e tecnologias que visam otimização em toda a cadeia de valor. Essas medidas são mais comuns em países com mão-de-obra mais qualificada que, por este motivo, concentram atividades de menor valor agregado em pequenas e médias empresas (PMEs) com menor investimento tecnológico (Telukdarie et al., 2018).

Para Goerzig e Bauernhansl (2018), PMEs do setor metalmecânico não estão preparadas para implementar as ferramentas da Indústria 4.0. Nos países emergentes, geralmente é constatada uma maior dificuldade para adotar tecnologias inovadoras nas fábricas (Hall \& Maffioli, 2008; Kumar \& Siddharthan, 2013). PMEs que pretendem acompanhar a tendência latente de digitalização e os conceitos da Indústria 4.0 devem identificar quais são os seus objetivos estratégicos (Kumar e Siddharthan, 2013). Por exemplo, empresas com foco em diferenciação devem investir em tecnologias voltadas ao desenvolvimento de produto em P\&D (Kaminski et al., 2008). Por outro lado, as que têm como objetivo baixo custo, produtividade ou flexibilidade operacional devem focar em tecnologias da Indústria 4.0 que envolvam smart manufacturing (Frank et al., 2019b). Para isso, é importante que haja 
incentivo governamental, estratégias de cooperação e criação de ecossistemas favoráveis ao desenvolvimento de PMEs (Dalenogare et al., 2018; Frank et al., 2019b). Segundo Frank et al. (2016), empresas brasileiras tendem a investir seus esforços em inovação em duas frentes. A primeira é de input de inovação, como atividades externas de Pesquisa e Desenvolvimento (P\&D) e comercialização, que tendem a ter um maior impacto no que tange à inovação. Já a segunda frente é a aquisição de novas máquinas e equipamentos que, por sua vez, costumam ter um aspecto mais negativo à percepção de inovação. Isso ocorre pois, de acordo com Frank et al. (2016), a aquisição de novas máquinas geralmente não configura inovação, mas, sim, uma atualização de tecnologias já ultrapassadas. Schumacher et al. (2016) desenvolveu um modelo de maturidade de Indústria 4.0 com nove dimensões e itens de maturidade, visto que as empresas percebem que os conceitos de Indústria 4.0 são muito complexos e não há uma estratégia clara de como orientar essa transformação digital. Outrossim, o modelo de Schumacher et al. (2016) ajusta-se ao nível de detalhes requeridos em aplicações práticas para empresas de manufatura. Quando um modelo é desenvolvido por pesquisadores para a indústria, pode ajudar a orientar as transformações industriais e a desenvolver novos modelos de negócio em conjunto com a adoção de tecnologias. Dessa forma, surge uma lacuna de pesquisa que envolve modelos de negócios e Indústria 4.0 em relação ao desenvolvimento industrial em pequenas e médias empresas. E, consequentemente, duas questões de pesquisa emergem: quais são os principais problemas enfrentados pelas empresas no setor metalmecânico? Como as tecnologias da Indústria 4.0 podem auxiliar na resolução de problemas?

Por esse motivo, este trabalho tem por objetivo identificar os principais problemas associados a modelo de negócios nas empresas do setor metalmecânico e apontar como as tecnologias da Indústria 4.0 podem auxiliar na resolução dos problemas. Para isso, foi realizado uma survey em empresas de pequeno e médio porte do setor metalmecânico, avaliando quais tecnologias são utilizadas atualmente, assim como as adaptações necessárias ao modelo de negócios e quais são as principais barreiras que devem ser superadas para viabilizar este processo, tendo como base o modelo de Schumacher et al. (2016), avaliou-se, consequentemente, como as empresas do setor metalmecânico podem usar a tecnologia para atingir as diferentes dimensões e itens de maturidade para o desenvolvimento da Indústria 4.0. A pesquisa foi conduzida com 25 empresas entre ferramentaria, fabricantes de moldes, fabricantes de ferramentas entre outras áreas de apoio a indústria metalmecânica. Posteriormente, realizaram-se a tabulação e a análise de resultados com base em análises descritivas. Os resultados foram condensados em forma de um framework para facilitar o entendimento. Com o framework, é possível entender quais as os principais problemas da implantação da Indústria 4.0 e como as tecnologias podem suportar essa transição em pequenas e médias empresas no setor metalmecânico.

Na seção 2, foram desenvolvidos e aprofundados os conceitos que compõem o referencial teórico e bibliográfico da pesquisa, com o objetivo de embasar o presente estudo de forma consistente. 
Já na seção 3 estão definidos e descritos os processos metodológicos de execução do trabalho. Na seção 4, desenvolvimento, ainda consta os detalhes da elaboração do questionário utilizado para identificar a relação das PMEs com as tecnologias da Indústria 4.0, bem como a avaliação do modelo de negócio adotado pelas empresas. Por fim, na seção 5, os resultados obtidos foram relacionados para propor soluções aos problemas raiz relacionados a modelo de negócios identificados no presente estudo.

\section{Referencial teórico}

\subsection{Nível de prontidão tecnológico e modelos de maturidade}

Para atravessar os desafios substanciais referentes a tecnologias de inovação radical da Indústria 4.0, é necessário gerenciar toda cadeia de valor de forma mais ágil e responsiva (Schumacher, 2016). Nesse sentido, a utilização de modelos de maturidade para realizar diagnósticos organizacionais e avaliar o nível em que as empresas se encontram é fundamental (Issa et al., 2018). Em geral, maturidade significa "estado do ser completo, perfeito ou pronto" (Simpson, 1989). Para Becker (2009), que estudou modelos de maturidade referentes à área de Tecnologia da Informação (TI), modelos de maturidade são instrumentos valiosos que permitem avaliar a situação atual de uma empresa, bem como identificar oportunidades de melhoria. Lu e Weng (2018) também citam que modelos de maturidade são utilizados como instrumentos para conceituar e medir a maturidade de uma organização, visando melhor entendimento do estado de maturação. Os modelos de maturidade auxiliam a identificar barreiras e desafios nas organizações. Atualmente, os principais desafios para área de manufatura estão relacionados a conceitos de inovação radical, como Internet das Coisas (IoT), Sistemas Ciber Físicos (CPS) e computação baseada em nuvem - tecnologias associadas à Indústria 4.0 (Schumacher, 2016). Para Kaminski et al. (2008), as melhores práticas para inovação não possuem um passo a passo ou regras fixas a serem seguidas, mas sim uma integração de tecnologias e abordagens benéficas para as empresas, de acordo com o seu grau de maturidade. Diferentemente de países desenvolvidos em que as empresas estão em um estágio de maturidade mais avançado, países emergentes enfrentam desafios maiores como o nível de prontidão tecnológica devido à sua baixa maturidade tecnológica e pouco conhecimento sobre as tecnologias da Indústria 4.0 e seus benefícios (Dalenogare et al., 2018; Guan et al., 2006).

Nesse sentido, diferentemente de países desenvolvidos que possuem altos investimentos em pesquisa e desenvolvimento (P\&D), desenvolvendo suas próprias tecnologias, países emergentes como o Brasil, costumam investir mais na aquisição de tecnologias ( Frank et al., 2016). Isso mostra que países emergentes precisam avaliar seu nível de prontidão antes de estabelecer um roadmap de maturidade para a Indústria 4.0 (Lu e Weng, 2018; Pacchini et al., 2019). Para isso, há a necessidade de analisar se as empresas possuem infraestrutura e capabilidades necessárias para lidar com a adoção de tecnologias 
(Castelo-Branco et al., 2019). No caso da Indústria 4.0, verificar se as empresas possuem o mínimo de suporte em tecnologias da comunicação e informação e automação para a adoção das tecnologias 4.0. Assim, como etapa preliminar a análise da maturidade, principalmente para PMEs em países emergentes, o nível de prontidão tecnológico deve ser investigado (Nick et al., 2019; Pacchini et al., 2019).

\subsection{Impactos da Indústria 4.0 nos modelos de negócio}

A Alemanha conta com uma das mais competitivas e fortes indústrias manufatureiras do mundo. Isso ocorre devido à alta especialização na área de pesquisa, de desenvolvimento de produto, de desenvolvimento de tecnologias inovadoras e do gerenciamento de processos industriais complexos (Li, 2018; Xu et al., 2018). O governo alemão através de uma parceria com empresas privadas e universidades apresentou um plano de digitalização da manufatura, assim introduzindo o termo Indústria 4.0 na feira tecnológica industrial de Hannover Messe em 2011 (Kagermann et al., 2013). Para incentivar esse crescimento, o governo alemão criou o chamado "High-TechStrategy 2020", lançado pelo Grupo de Promotores de Comunicação da Industry-Science Research Alliance, que deu início à implementação dos conceitos da Indústria 4.0 para aumento de competitividade (Kagermann et al., 2013). A Indústria 4.0 se baseia em um estágio tecnológico em que máquinas não só executam operações, mas têm capacidade de se conectar em rede, interagir e trocar informações, transformando fábricas em organismos inteligentes que recolhem e distribuem informação em toda cadeia de valor através de IOT e CPS (L. Wang et al., 2015). Para Kagermann (2013), essas tecnologias possibilitam a criação de redes que incorporam todo processo de fabricação, convertendo fábricas em ambientes inteligentes. Além de facilitar a flexibilização da produção, a digitalização oferece oportunidades de rastreabilidade e gerenciamento diferenciados com o uso de ferramentas como big data analytics (Kagermann et al., 2013). Para manter vantagem competitiva, indústrias do mundo todo terão que se concentrar nas suas competências que agregam mais valor, enquanto descentralizam operações periféricas com parceiros (Scheer, 2013). Isso potencialmente modifica o escopo do modelo de negócio das empresas, fazendo com que o foco e a gestão mudem para ser o mais eficiente possível (Brettel et al., 2014). Ibarra (2018) analisa os impactos da Industria 4.0 em diferentes modelos de negócios e identifica que, por um lado, existem três abordagens que aproximam as empresas da Indústria 4.0 (orientação a serviços, ecossistemas em rede e orientação ao cliente). Por outro lado, essas abordagens geram implicações nos componentes do modelo de negócio, como melhoria no modelo tradicional, reconfiguração dos ecossistemas de valor em rede e nova tipologia baseada na personalização dos produtos e serviços (Ibarra, 2018). 
Amit e Zott (2001) definem modelo de negócio como sendo o conteúdo, a estrutura e a governança das transações projetadas de forma a criar valor por meio da exploração de oportunidades de negócios. Na opinião de Chesbrough (2010), a mesma ideia ou tecnologia levada ao mercado por modelos diferentes produzirá resultados diferentes. Atualmente, uma das ferramentas mais utilizada para estruturar e identificar um modelo de negócios é o Bussines Model Canvas, desenvolvido por Osterwalder e Pigneur (2010). O modelo de grandes empresas e suas posições no mercado possibilitam o enfoque em operações que agregam maior valor a suas marcas, enquanto terceirizam as atividades que, para elas, agregam menos valor (Pisano \& Shih, 2012). Já as PMEs desempenham um papel fundamental na manutenção do crescimento das grandes economias, formando uma espinha dorsal que impulsiona o crescimento de um determinado cluster (Reynolds e Uygun, 2018). Para que as grandes empresas possam focar no crescimento e desenvolvimento, necessitam que empresas menores assumam atividades menos complexas, porém mantendo a qualidade (Reynolds e Uygun, 2018). Berger (2014) chama de "democracia industrial" a difusão das fronteiras entre informação e mundo físico, que reduzem as barreiras de entrada para empresas menores no processo fabril de grandes empresas. Existem oportunidades significativas para PMEs e startups desenvolverem serviços business-to-business (B2B) com enfoque na Indústria 4.0, como por exemplo, a aplicação de prototipagem (Kagermann et al., 2013). Rong et al. (2018) (2018), a partir de uma análise em empresas de impressão 3D, afirmam que as empresas necessitam compreender de forma eficaz a gestão do ecossistema de negócios e seus stakeholders para entender a viabilidade de mudança dos modelos de negócios. Assim, a transformação tecnológica, através da digitalização, é capaz de conectar PMEs a grandes empresas de forma mais eficiente e eficaz (Goerzig \& Bauernhansl, 2018);

\subsection{Digitalização em PMEs}

A digitalização é um processo que reestrutura a empresa. Em uma reestruturação, seja de aspectos internos ou do modelo de negócios, pequenas mudanças na forma como uma empresa opera em uma determinada área transforma os paradigmas de desenvolvimento dos seus serviços (Rifkin, 2001). Segundo Sok e O'Cass (2011), a complementariedade de recursos e o desempenho baseado em inovação devem ser o enfoque de PMEs. Goerzig e Bauernhansl (2018) apresentam os primeiros passos para uma nova abordagem em arquiteturas corporativas para transformação digital em PMEs. Para os autores, essa abordagem deve ser mais ágil e, portanto, mais próxima do cliente. Nesse método, a abordagem é dividida em ciclo macro, que representa a arquitetura de uma PME inteira, e ciclo micro, que diz respeito a funções únicas de mais fácil implementação e testes. Além disso, existem decisões estratégicas importantes como: escala, velocidade e escopo de aplicação da tecnologia digital na empresa (Goerzig e Bauernhansl, 2018). As tecnologias digitais são fundamentais para o 
desenvolvimento da Indústria 4.0. No Quadro 1, diversas tecnologias relacionadas à Indústria 4.0 são apresentadas.

Quadro 1

Tecnologias da Indústria 4.0 e suas definições

\section{Technologies}

Enterprise Resource Planning (ERP)

Manufacturing Execution System

(MES)

Supervisory Control and Data Acquisition (SCADA)

Internet das Coisas (IoT)

Computação em nuvem

Big data

Analytics e Inteligência Artificial

Rede elétrica inteligente (smart grid)

Impressora 3D

Robôs colaborativos

Robôs industriais

Linhas flexíveis

\section{Definition}

Sistemas que podem integrar todos os dados e processos necessários para gerenciar uma empresa (Gilchrist, 2016).

Sistemas que trabalham em tempo real para permitir o controle de múltiplos elementos do processo de produção (Jeschke et al., 2017)

Sistemas de monitoramento de operações de chão de fábrica através da coleta de dados em tempo real (Jeschke et al., 2017).

Sistemas de dispositivos de computação inter-relacionados e dispositivos físicos que estão conectados à Internet com a capacidade de transferir dados por uma rede sem exigir interação homem-homem ou homem-computador (Fahmideh \& Zowghi, 2020; Frank et al., 2019b)

Tipo de computação que depende de recursos de computação compartilhados, em vez de ter servidores locais ou dispositivos pessoais para lidar com aplicativos (Fan et al., 2019; Frank et al., 2019b).

Grande quantidade de dados acumulados que podem ser analisados computacionalmente para revelar padrões, tendências e associações, especialmente relacionadas ao comportamento e interações humanas (Frank et al., 2019b; Gilchrist, 2016)

O Analytics é a capacidade de analisar dados com técnicas avançadas, como inteligência artificial. A inteligência artificial é um ramo abrangente da ciência da computação, preocupado com a construção de máquinas inteligentes capazes de executar tarefas que normalmente exigem inteligência humana (Frank et al., 2019b; Sturgeon, 2019)

Sistemas de rede elétrica para otimizar a eficiência energética com troca de informações em tempo real, integrando tecnologias de informação e comunicação à rede elétrica existente (Park \& Kim, 2014).

Máquinas versáteis de manufatura para sistemas flexíveis de manufatura (FMS), transformando modelos 3D digitais em produtos físicos (Weller et al., 2015).

Sistemas robóticos com sensores e processadores, permitindo a cooperação direta com operadores humanos (Bartodziej, 2017a, 2017b; Gilchrist, 2016) (Bartodziej, 2017; Gilchrist, 2016).

Processos automatizados por mecanismos robóticos internos, sem intervenção humana (Gilchrist, 2016; Tao et al., 2018).

Sistemas auto-organizados (linhas de produção) que podem ser reconfigurados dinamicamente para se adaptar a diferentes tipos de produtos, onde uma informação massiva é coletada e 
Technologies

Definition

\begin{tabular}{|c|c|}
\hline Technologies & Definition \\
\hline & $\begin{array}{l}\text { processada para tornar o processo de produção transparente } \\
\text { (L. Wang et al., 2015; S. Wang et al., 2016) }\end{array}$ \\
\hline Machine vision & $\begin{array}{l}\text { Detecção de posicionamento de objetos por sistemas de } \\
\text { processamento de imagem para controle de qualidade (Tao et } \\
\text { al., 2018). }\end{array}$ \\
\hline Comissionamento virtual & $\begin{array}{l}\text { Debug de dados reais do equipamento em um ambiente } \\
\text { virtual, simulando virtualmente o equipamento de automação, } \\
\text { validando sua operação na linha de produção (Jeschke et al., } \\
\text { 2017). }\end{array}$ \\
\hline Manufatura digital & $\begin{array}{l}\text { Uso de sistemas de gerenciamento de dados com tecnologias } \\
\text { de gerenciamento de dados e tecnologias de simulação para } \\
\text { otimização da fabricação, antes de iniciar a produção, } \\
\text { suportando as fases de aceleração (Rüßmann et al., 2015). }\end{array}$ \\
\hline Realidade virtual e aumentada & $\begin{array}{l}\text { Integração de imagens da realidade com informações geradas } \\
\text { pela computação. A integração do real com o mundo virtual } \\
\text { (Frank et al., 2019b; Rüßmann et al., 2015). }\end{array}$ \\
\hline $\begin{array}{l}\text { Desenho assistido por computador } \\
\text { (CAD/CAM) }\end{array}$ & $\begin{array}{l}\text { Desenvolvimento de projetos e planos de trabalho para } \\
\text { produtos e manufatura baseados em sistemas } \\
\text { computadorizados (Scheer, 2013). }\end{array}$ \\
\hline
\end{tabular}

Fonte: Adaptado de Dalenogare et al. (2018) e Benitez et al. (2020).

O aumento da digitalização traz maior complexidade à organização tornando as áreas de estratégia de negócios e TI mais interligadas - esta fusão é denominada estratégia de negócios digitais (Bharadwaj et al., 2013). A aplicação de processos baseados em TI não apenas expande as possibilidades de desenvolvimento de processos, mas torna os processos em si mais complexos. Isso evidencia que novos métodos e modelos de negócio são necessários para ajudar a colocar a estratégia em ação (AlDebi et al., 2008). O estudo "Indústria 4.0: novo desafio para a indústria brasileira", feito pela Confederação Nacional da Indústria (CNI), em 2016, mostra que, no Brasil, os avanços proporcionados pela Indústria 4.0 dependem em grande parte: da melhor compreensão dos ganhos da digitalização no aumento da produtividade, das oportunidades de novos negócios, da flexibilidade, da customização da produção e da redução do tempo de processamento para lançar novos produtos (CNI, 2016). Para acelerar esse processo, é necessário maior acesso à informação e identificação de parceiros para diminuir a incerteza e mudar a cultura da empresa (PWC, 2016).

\subsection{Setor metalmecânico brasileiro}

O setor metalmecânico é essencial para o contexto brasileiro, visto que ele pode impactar diversos outros setores do país, como agricultura, guerra e transporte (Doce \& de Oliveira Gomes, 2018). Logo, para alguns, o setor metalmecânico é o mais importante da indústria brasileira, porque é capaz de gerar novas empregos e a aumentar as receitas nas empresas (Kaminski et al., 2008). Como é um setor essencial para economia, quando existem inovações em relação a produtos e processos, elas 
podem ajudar a diminuir os desperdícios, consumo de energia e de água e tem um impacto positivo no meio ambiente (Eliana Andrea Severo et al., 2017), o que pode desenvolver uma região socialmente, economicamente e ambientalmente. Na região Sul do Brasil, há um cluster do setor metalmecânico, e as empresas que se instalam em clusters industriais geralmente têm como objetivo reduzir os seus custos e melhorar a imagem em relação aos seus concorrentes perante os consumidores ( Severo et al., 2015). Por exemplo, o setor metalmecânico automotivo possui mais de 2500 empresas de médio e pequeno porte (o que corresponde 95\% de todas as empresas), gerando mais de 60.000 empregos no cluster metalmecânico da serra gaúcha ( Severo et al., 2015). Além disso, a indústria metalmecânica tem um foco grande em inovação, almejando aprimorar os processos de suas operações, desenvolvendo formas de melhorar a comunicação entre áreas de produção e estoque além de diminuir itens no estoque, aumentando, consequentemente, a eficiência da linha de produção (Dorion et al., 2014).

\section{Procedimentos metodológicos}

A Figura 1 representa as etapas de elaboração do estudo em questão, subdividido em quatro partes para melhor compreensão.

Figura 1

\section{Fluxograma de trabalho}

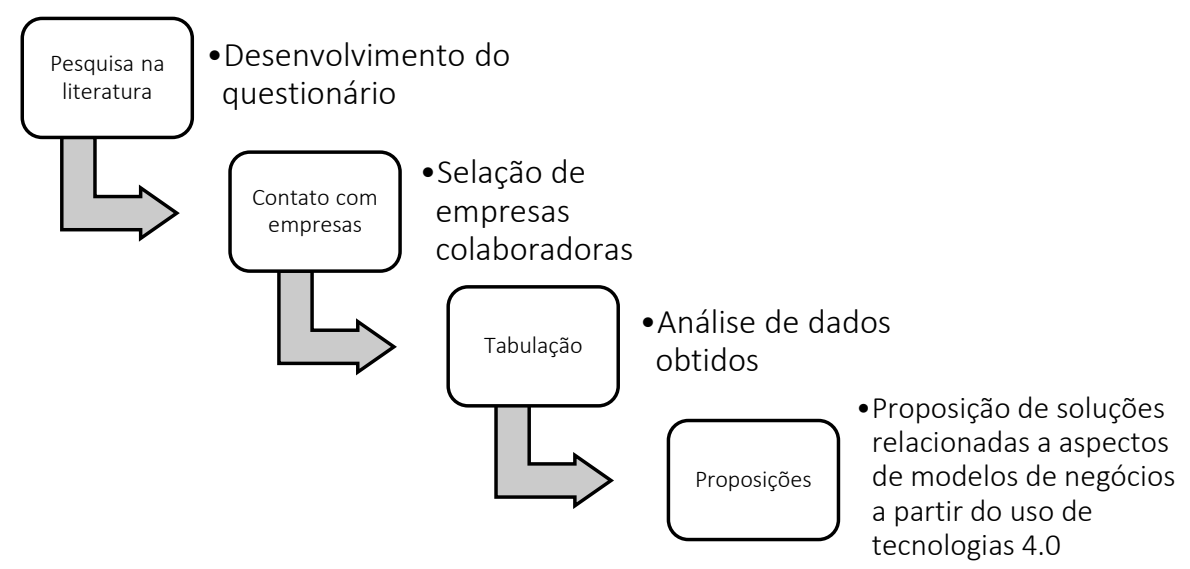

Fonte: Elaborado pelos autores.

O setor metalmecânico, considerando em particular o contexto das pequenas empresas, precisa se desenvolver a fim de se tornar competitivo em relação a seus fornecedores, portanto é imprescindível mitigar as barreiras técnicas com intuito de atingir ganhos econômicos e ambientas com a aquisição de máquinas e equipamentos mais eficientes (Leite et al., 2019). Além disso, como já mencionado anteriormente, o setor metalmecânico possui diversos clusters industriais no Brasil, por isso é fundamental seu estudo, visto que não é só adoção de tecnologias que desenvolve as empresas, 
mas também as estratégias que eles abordam (Basso et al., 2005). Por exemplo, o setor metalmecânico na região de Sorocaba é composta por um parque industrial (cluster) em que atuam empresas de diferentes áreas: equipamentos, indústrias automotivas e elétricas (Amato Neto, 2009). No entanto, além dessas empresas que compõem o cluster, há pequenas e médias empresas responsáveis pelo fornecimento de serviços de apoio e fundamentais para economia da região (Amato Neto, 2009). Já, na região sul do Brasil, no estado do Rio Grande do Sul, existe um cluster do setor metalmecânico e automotivo da Serra Gaúcha. O cluster da região da Serra Gaúcha é fundamental para que as empresas presentes no cluster garantam vantagem competitiva em relação a recursos, porém, em relação a aspectos geográficos, e comparando o cluster da região da serra Gaúcha com outros clusters do metalmecânico, os custos de distribuição e logísticos inviabilizam a comercialização dos produtos para região centro-norte do Brasil, visto que o transporte é rodoviário na maioria das vezes, o que encarece o preço do produto (Witzel, 2017). Por isso, é imprescindível identificar tecnologias e modelos de negócios que garantam vantagem competitiva para empresas do setor metalmecânico na região sul do Brasil.

Para tanto, inicialmente, foi desenvolvido um questionário que visa identificar o nível de utilização tecnológica das empresas estudadas, bem como a importância dos conceitos da Indústria 4.0 percebida pelos gestores. Para isso, foi realizada uma revisão bibliográfica para chegar à base de dados e pesquisas que pudessem auxiliar no diagnóstico da situação atual e na resolução de problemas a partir do uso de tecnologias da Indústria 4.0 no setor metalmecânico. O questionário usou como referência as dimensões de maturidade citadas por Schumacher (2016), apresentadas e explicadas no Quadro 2. Já as tecnologias utilizadas (por exemplo, CAD, big data analytics, impressão 3D) para analisar o desenvolvimento tecnológico das empresas estão presentes nos estudos de Dalenogare et al. (2018) e Frank et al. (2019b) (Quadro 1). Na pesquisa, as empresas participantes foram convidadas a dar notas de 1 (não se aplica) a 5 (se aplica totalmente) para definir o grau de utilização de determinada tecnologia ou conceito relacionado a Indústria 4.0 e modelo de negócios dentro da empresa. 


\section{Quadro 2}

Dimensões para modelo de maturidade da Indústria 4.0

Dimensão

Estratégia

Liderança

Clientes

Produtos

Operações

Cultura

Pessoas

Governança

Tecnologia

\section{Exemplo de item de maturidade}

Implementação dos conceitos e tecnologias da Indústria 4.0, recursos disponíveis para realização, adaptação de modelos de negócios.

Disposição de líderes, competências e métodos de gestão, existência de coordenação central para Indústria 4.0.

Utilização de dados de clientes, digitalização de vendas/serviços, competência de mídia digital do cliente.

Individualização de produtos, digitalização de produtos, integração de produtos em outros sistemas.

Descentralização de processos, modelagem e simulação, colaboração interdisciplinar, interdepartamental.

Partilha de conhecimento, inovação aberta e colaboração entre empresas, comunicação na empresa.

Competências, informação e comunicação dos colaboradores, abertura de colaboradores a novas tecnologias, autonomia dos colaboradores

Regulamentos trabalhistas para indústria 4.0, adequação de padrões tecnológicos, proteção de propriedade intelectual.

Existência de tecnologias modernas; Tecnologias da Informação e Comunicação (TIC); utilização de dispositivos móveis; utilização de comunicação máquina a máquina.

Fonte: Schumacher et al. (2016).

O questionário também se respalda no relatório elaborado pela CNI, que realizou uma pesquisa aprofundada na indústria brasileira identificando o impacto da Indústria 4.0 para o desenvolvimento da indústria nacional (CNI, 2016). O relatório abrange 29 diferentes setores da indústria brasileira e analisa também o setor metalmecânico separadamente. A segunda etapa foi identificar empresas dispostas a participar do estudo. Para isso, foram contatadas 70 empresas associadas a ABINFER (Associação Brasileira da Indústria de Ferramentais) por e-mail através do auxílio do representante da entidade e mais 30 empresas do setor metalmecânico do sul do país por ligações telefônicas, totalizando 100 empresas, o que se trata uma limitação de escopo. Além disso, antes de ser enviado para os respondentes, o questionário passou por uma validação acadêmica com especialistas da Indústria 4.0 e, complementarmente, foram usadas técnicas para que as varáveis ficam temporalmente e espacialmente separadas (Podsakoff et al., 2012). Os respondentes foram escolhidos, visto que eles são capazes de realizar escolhas estratégias para a empresa, visto que o modelo de Schumacher et al. (2016) e utilizado por outros artigos de Indústria 4.0 com foco em pequenas e médias empresas (Benitez et al., 2020; Kahle et al., 2020).

Os questionários foram enviados por e-mail através de planilhas em formato Excel. Também foram realizadas ligações telefônicas para empresas que mandaram respostas incompletas para salientar a importância do estudo e do questionário totalmente respondido. Ao final, 25 responderam 
ao questionário, atingindo um percentual de resposta de $25 \%$. Todas as empresas selecionadas são categorizadas como PMEs conforme classificações adotadas por órgãos de pesquisa industriais e nacionais como a CNI e IBGE (n<500 funcionários). Esses órgãos são reconhecidos por fazerem pesquisas industriais a larga escala, como a pesquisa de inovação (PINTEC) e surveys como a da pesquisa de Indústria 4.0 da CNI (2016) uma das mais conhecidas sobre o tema no país. As empresas estão situadas na região sul e sudeste do Brasil, são de pequeno e médio porte, ou seja, possuem menos de 500 funcionários, e fazem parte da cadeia de suprimentos de grandes empresas (PINTEC, 2017; CNI, 2016). Nessa cadeia de suprimentos, ocorre um significativo investimento em tecnologias, visto que estes aportes podem corresponder a uma diferenciação competitiva na indústria manufatureira, porém, despendem alto custo para a implementação. Por esse motivo, o questionário foi aplicado em sua maioria com diretores e executivos que, além de ter uma visão mais ampla do negócio, são as pessoas que podem colocar em prática os resultados obtidos, como realizado em outros estudados da área de indústria 4.0 (Benitez et al., 2020; Kahle et al., 2020).

Após essa etapa, os dados coletados geraram notas para o desenvolvimento tecnológico das empresas participantes em comparação com os dados obtidos pela CNI (2016). De acordo com as respostas obtidas, foi possível identificar o nível de utilização das tecnologias relacionadas à Indústria 4.0, bem como, as dimensões de maturidade de Schumacher (2016) do modelo de negócios em que as empresas têm maior desenvolvimento e onde possuem maior carência. Por fim, o artigo utiliza os dados obtidos com a survey para propor soluções para os problemas raiz identificados no modelo de negócios das empresas utilizando as tecnologias da Indústria 4.0 que melhor se relacionam com os problemas identificados.

Para análise de dados, seguiu-se um protocolo de codificação de pesquisa presente no Quadro 3 com identificação de tecnologias, dimensões e modelos de negócios. A partir do quadro, foi possível desenvolver o protocolo de codificação da pesquisa. 


\section{Quadro 3}

Protocolo de codificação de pesquisa

1ํ Passo: Identificação das tecnologias

Tecnologias:

20 Passo: Cruzamento das Tecnologias com as Dimensões de Schumacher et al. (2016)

Tecnologias/Dimensões Operação Estratégia Liderança

\begin{tabular}{|c|c|c|c|c|}
\hline $\mathrm{CNC}$ & $x$ & $x$ & $x$ & $x$ \\
\hline CAD & $x$ & $x$ & & \\
\hline Ciberfísicos & & $x$ & & \\
\hline
\end{tabular}

3ㅇ Passo: Cruzamento do modelo de negócios com as Dimensões do Schumacher et al. (2016)

\begin{tabular}{|c|c|c|c|c|}
\hline $\begin{array}{c}\text { Modelo de } \\
\text { Negócios/Dimensões }\end{array}$ & Operação & Estratégia & Liderança & $\ldots$ \\
\hline Processos decentralizados & $X$ & $X$ & $X$ & $X$ \\
\hline Pós venda & $x$ & $x$ & & \\
\hline$\ldots$ & $X$ & & & \\
\hline
\end{tabular}

Fonte: Elaborado pelos autores.

\section{Resultados}

Após receber os questionários respondidos, foi possível verificar que a grande maioria das empresas que participaram da pesquisa são de pequeno porte, como característica da região da região sul do país na área metalmecânico. Além disso, quase metade dos questionários foram respondidos por gerentes ou diretores, como mostra a Tabela 1, o que está alinhado com outros trabalhos desenvolvidos na área de Indústria 4.0 (Benitez et al., 2020; Kahle et al., 2020). Tanto a validade do questionário quanto das respostas foi conduzida com pesquisadores especialistas da área de indústria para garantir a confiabilidade do estudo (Benitez et al., 2020; Podsakoff et al., 2012). Também há um considerável número de analistas ou técnicos que responderam à survey, o que é um ponto de destaque, pois eles são os profissionais mais capacitados juntamente com os gerentes e diretores a responderem às questões relacionadas à Indústria 4.0. 
Tabela 1

Perfil dos respondentes

\begin{tabular}{clc} 
Categorias & \multicolumn{1}{c}{ Descrição } & $(\%)$ \\
\multirow{2}{*}{ Tamanho } & Pequena (<100 colaboradores) & $80 \%$ \\
& Média (100-500 colaboradores) & $20 \%$ \\
\cline { 2 - 3 } Função & Gerente ou diretor & $48 \%$ \\
& Analista ou técnico & $32 \%$ \\
& Supervisor ou coordenador & $8 \%$ \\
& Outros & $12 \%$
\end{tabular}

Fonte: Elaborada pelos autores.

\subsection{Tecnologias 4.0}

As respostas da survey foram tabuladas de forma a serem alocadas em diferentes grupos, organizados por percentual de utilização das tecnologias para o desenvolvimento industrial. As notas 4 e 5 dadas pelas empresas para determinada tecnologia serviram como identificação de maior grau de utilização no setor metalmecânico. Notou-se que aproximadamente 90\% das empresas dominam tecnologias identificadas como pertencentes à terceira revolução industrial, como CNC, CAD e CAM. Ou melhor, $90 \%$ das empresas que foram avaliadas responderam 4 ou mais para a utilização dessas tecnologias. Já as notas 1, 2 e 3 foram associadas com a baixa aderência. Nesse sentido, destacaram-se as tecnologias típicas da Indústria 4.0, como robôs e manufatura aditiva (Benitez et al., 2020; Dalenogare et al., 2018; Frank et al., 2019b), visto que apenas 12\% das empresas deram notas 4 e 5 para utilização dos robôs colaborativos. Dessa forma, há oportunidade de crescimento do uso de robôs e manufatura aditiva no setor metalmecânico. A Tabela 2 consolida o percentual de utilização das tecnologias para o desenvolvimento industrial seguindo o protocolo de codificação do Quadro 2. 


\section{Tabela 2}

Percentual de utilização das tecnologias para o desenvolvimento industrial

\begin{tabular}{|c|c|c|}
\hline Categorias & Descrição das tecnologias & $\begin{array}{l}\text { (\%) de utilização da } \\
\text { tecnologia }\end{array}$ \\
\hline \multirow{3}{*}{$\begin{array}{l}\text { Máquinas e } \\
\text { processos }\end{array}$} & Máquinas com Controle Numérico Computadorizado (CNC) & $92 \%$ \\
\hline & $\begin{array}{l}\text { Máquinas programadas por sistemas de manufatura como } \\
\text { CAD/CAM }\end{array}$ & $88 \%$ \\
\hline & Incorporação de novas tecnologias nos processos & $68 \%$ \\
\hline \multirow{5}{*}{ Função } & Customização de produtos (constante e acessível) & $56 \%$ \\
\hline & Sistema gestão (SAP) & $56 \%$ \\
\hline & Disponibilização de dados dos produtos aos clientes & $52 \%$ \\
\hline & Coleta de dados em tempo real no chão de fábrica & $52 \%$ \\
\hline & Simulação industrial para previsão de demanda & $48 \%$ \\
\hline \multirow{10}{*}{$\begin{array}{l}\text { Digitalização e } \\
\text { integração }\end{array}$} & Cibersegurança & $44 \%$ \\
\hline & Computação em nuvem & $40 \%$ \\
\hline & Big data analytics & $40 \%$ \\
\hline & Internet das coisas (IoT) & $40 \%$ \\
\hline & $\begin{array}{l}\text { Padronização nos protocolos de comunicação industrial entre } \\
\text { máquinas (Machine-to-Machine) }\end{array}$ & $40 \%$ \\
\hline & Layout flexível (produção) & $40 \%$ \\
\hline & Sistemas ciberfísicos & $40 \%$ \\
\hline & Sensoreamento digital (ex.: trouchprobe) & $36 \%$ \\
\hline & $\begin{array}{l}\text { Dispositivos digitais de segurança (ex.: rastreabilidade através de } \\
\text { RFID) }\end{array}$ & $32 \%$ \\
\hline & Monitoramento e controle de eficiência energética nos processos & $32 \%$ \\
\hline \multirow{3}{*}{ Flexibilização } & Robôs autônomos & $16 \%$ \\
\hline & Manufatura aditiva (impressão 3D) & $16 \%$ \\
\hline & Robôs colaborativos (homem-máquina) & $12 \%$ \\
\hline
\end{tabular}

As perguntas referentes às tecnologias utilizadas pelas empresas foram agrupadas em quatro principais seções de acordo com o grau de utilização. Para organizar as respostas, optou-se pela ordem da mais aplicada para menos aplicada, evidenciando assim quais áreas tecnológicas recebem maior investimentos das PMEs. Com relação à distribuição das respostas, foi possível verificar uma tendência já esperada de maior utilização das tecnologias mais consolidadas no mercado e menor das tecnologias atuais e disruptivas, ainda não tão consolidadas no mercado. Ou seja, as mais largamente aplicadas foram as tecnologias estão agrupadas na primeira categoria (acima de 65\%), enquanto na segunda permeiam tecnologias relacionadas a funções, tendo o grau de utilização entre $41 \%$ e $60 \%$. No terceiro grupo, as tecnologias 4.0 mais leves (em custo e aplicação) e, no último grupo, tecnologias 4.0 mais pesadas, no caso, que necessitam de maior investimento financeiro (CNI, 2016; Dalenogare et al., 2018; Frank et al., 2019b). As tecnologias encontradas no primeiro grupo transformaram a produção manual das indústrias (torno convencional, fresadora, plaina, etc.) em uma produção digital (centros de usinagem $\mathrm{CNC}$, torno $\mathrm{CNC}$ ) tornando possível a confecção de peças mais complexas, precisas, rápidas e escaláveis. Em vez de um operador realizar o trabalho dentro de suas limitações e do equipamento, um 
programa de computador que abrange uma gama muito maior de operações realiza todas as tarefas por meio de um sistema de coordenadas, e cabe ao operador apenas o setup, a manutenção, a troca de ferramentas e a inspeção. No segundo grupo, estão tecnologias e conceitos que representam inovação em produtos e na fábrica. As mais aplicadas são a customização dos produtos para melhor atender os requisitos dos clientes e a utilização de sistemas de gestão para melhor gerir e organizar a empresa. Em seguida, há tecnologias praticamente dependentes uma da outra, que são a coleta de dados no chão de fábrica e a disponibilização dos dados obtidos para os clientes, como propriedades do material, adquiridas durante o processo. Essas tecnologias em conjunto com o SAP permitem um monitoramento e controle do que ocorre na fábrica e nos produtos. Já, no terceiro bloco, encontramos tecnologias relacionadas a digitalização e integração dos elementos da fábrica. Tecnologias como Big Data, loT e armazenamento em nuvem contribuem para a análise de dados e tomada de decisão em tempo real. Essas funcionalidades representam um grande salto em direção à Indústria 4.0, pois permitem organizar e gerir os dados de forma sistêmica, facilitando a identificação de perdas, garantindo a análise periódica dos dados e a utilização deles para transformar a indústria tradicional. Além disso, são capazes de digitalizar a fábrica, ou seja, tornar o mundo real em digital, possibilitando assim, a simulação e monitoramento de dados, gerando um sistema ciberfísico. Além disso, tecnologias como loT, M2M e sistemas ciberfísicos possibilitam a integração de todos os elementos da fábrica, verticalizando seus processos industriais. Já os sensores digitais, dispositivos de rastreamento, e monitoramento da eficiência energética, são ferramentas que abastecem as tecnologias anteriores. Por fim, o layout flexível, juntamente com a comunicação entre as máquinas, torna o ambiente fabril muito mais autônomo e sinérgico. No último bloco, estão tecnologias de flexibilização da produção, que ainda encontram diversas barreiras para implementação. Entre os principais limitadores, estão motivos financeiros, por ainda serem consideradas tecnologias caras para as PMEs, e o grande impacto nos processos da indústria, que resultam na necessária quebra de paradigmas da indústria e em uma abordagem resiliente. Atualmente, a utilização de robôs e manufatura aditiva pode tornar-se para indústria nacional o que o CNC representou nos anos 80 e 90, ou seja, tecnologias inovadoras, inicialmente caras, mas que ganharam espaço como ferramentas imprescindíveis para uma produção moderna e eficiente (Balletti et al., 2017; D’aveni, 2013).

\subsection{Modelo de negócio}

Para analisar as questões referentes ao modelo de negócios, foram selecionadas as mesmas escalas, porém organizadas pela porcentagem de não utilização. Assim, ficaram evidentes as dimensões menos usadas. Desta forma, pode-se destacar quais áreas dos modelos de negócio o setor metalmecânico apresenta maiores dificuldades, para posteriormente serem sugeridas soluções 
alinhadas às tecnologias mais adequadas. A Tabela 3 consolida os resultados referentes ao modelo de negócios.

Tabela 3

Percentual de associação a problemas relacionados aos modelos de negócio

\begin{tabular}{|c|c|c|}
\hline Dimensão & Problemas & $\begin{array}{l}\text { Associação } \\
\text { (\%) }\end{array}$ \\
\hline Operação & Processos engessados (não descentralizados) & $68 \%$ \\
\hline Estratégia & Falta de ajuste as oscilações de mercado & $48 \%$ \\
\hline Clientes & Fraco pós-venda & $48 \%$ \\
\hline Governança & Problemas de proteção à propriedade intelectual & $48 \%$ \\
\hline Produto & Problemas em relação a informações digitalizadas dos produtos & $32 \%$ \\
\hline Tecnologia & Baixa utilização de meios digitais na produção & $32 \%$ \\
\hline Tecnologia & $\begin{array}{l}\text { Utilização de documentos físicos e um único banco de dados armazena as } \\
\text { informações }\end{array}$ & $32 \%$ \\
\hline Produto & Facilidade em customizar a produção & $28 \%$ \\
\hline Operação & Capacidade instalada próxima da capacidade efetiva & $28 \%$ \\
\hline Governança & Atualização periódica das tecnologias adoptadas & $28 \%$ \\
\hline Liderança & Conhecimento explícito da liderança & $24 \%$ \\
\hline Cultura & Cultura organizacional orientada à inovação & $24 \%$ \\
\hline Pessoas & Capacitação dos colaboradores & $24 \%$ \\
\hline Estratégia & Estratégia orientada a gerar valor para os clientes & $20 \%$ \\
\hline Liderança & Conhecimento tácito da liderança & $20 \%$ \\
\hline Pessoas & Ambiente organizacional com foco nas pessoas & $20 \%$ \\
\hline Cultura & Cultura organizacional orientada à mudança & $16 \%$ \\
\hline Clientes & Desenvolvimento de uma boa comunicação com os clientes & $12 \%$ \\
\hline
\end{tabular}

Na segunda etapa do questionário, foram propostas 18 perguntas, sendo duas referentes a cada dimensões do modelo de Schumacher (2016) (Operação; Estratégia; Clientes; Governança; Produto; Tecnologia; Liderança; Cultura; Pessoas). Para 'Operação', foi questionada a taxa de utilização fabril e centralização dos processos com o objetivo de medir a eficiência da operação, bem como a difusão da informação. 'Estratégia' indagou sobre variações no modelo de negócios e relação com os clientes, demonstrando a tendência à inovação e à adaptação para atender aos clientes. 'Governança' abordou a propriedade intelectual e a atualização de tecnologias, pois são referentes a decisões gerenciais. Sobre 'Clientes' as perguntas aprofundaram os temas de comunicação e pós-venda, que são complementares na relação com o público. As questões de 'Liderança' focaram na capacitação e na experiencia para demonstrar a aptidão dos gerentes. 'Cultura' questionou se a empresa está aberta ou se é voltada à inovação. 'Produto' ateve-se à customização e aos produtos digitais, elo entre tecnologia e gestão do 
modelo. 'Tecnologia' focou em armazenamento de dados e digitalização, necessários para Indústria 4.0. Por fim, sobre 'Pessoas' foi questionado acerca do ambiente de trabalho e da capacitação dos colaboradores, evidenciando a motivação dos trabalhadores.

Com relação às dimensões de Schumacher (2016), as respostas foram agrupadas destacando as questões que apresentaram menor percentual de utilização das empresas, correspondendo a perguntas relacionadas à operação, à estratégia, a clientes e à governança. As quatro questões menos aplicadas se referem a 4 dimensões diferentes, ou seja, não há uma dimensão que se destaque muito mais do que as outras, porém as quatro podem ser justificadas por características da pequena e média indústria. Em pequenas empresas, é comum que haja centralização dos processos, além da omissão de informações importantes, concentrando essas informações nas mãos de poucas pessoas. Da mesma forma, o modelo de negócio fica refém dos clientes mais fortes, ou seja, o modelo só se modifica se os clientes se modificarem. Com relação ao pós-venda, a falta de informações digitalizadas dificulta o relacionamento ágil com os clientes, e a proteção à propriedade intelectual tende a adquirir mais importância a medida de que as informações são difundidas a terceiros.

\subsection{Problemas raiz no modelo de negócios}

Com o uso do protocolo de codificação foi possível, fazer a relação entre modelos de negócios e as tecnologias. Dessa forma, conseguiu-se identificar os principais problemas em relação a utilização de tecnologias em empresas manufatureiras. Tendo em vista que o questionário também foi respondido por gerentes e diretores, notou-se uma tendência a supervalorizar o modelo de negócio. Já para as tecnologias, foi possível inferir que há um considerável nível de utilização em três dos quatro agrupamentos por corresponder a tendência de desenvolvimento tecnológico e apresentar compatibilidade de aplicação na indústria com custo para aplicação, ou seja, tecnologias menos complexas e acessíveis apresentaram alta aderência, enquanto tecnologias de inovação radical e caras (quarto agrupamento), menor utilização. Com isso, podemos relacionar as dificuldades no modelo de negócio com as tecnologias, como mostra o Quadro 4. 


\section{Quadro 4}

Proposta de soluções para problemas raiz de tecnologias

$\begin{array}{ll}\text { Problemas raiz em relação do modelo } & \text { Tecnologias } 4.0 \text { associadas para solucionar problemas raiz } \\ \text { de negócios } & \text { Sistemas de Execução de Manufatura e Controle de } \\ & \text { Supervisão e Aquisição de Dados } \\ & \text { Big data e análise de dados } \\ & \text { Serviços em nuvem para produtos } \\ & \text { Cibersegurança e loT } \\ \text { Processos engessados (não } & \text { Sistemas ciberfísicos } \\ \text { descentralizados) } & \text { M2M }\end{array}$

$\begin{array}{ll} & \text { Linhas de fabricação flexíveis } \\ & \text { Sistemas de Execução de Manufatura e Controle de } \\ & \text { Supervisão e Aquisição de Dados } \\ \text { Falta de ajuste as oscilações de } & \text { Serviço em nuvem para produtos } \\ \text { mercado } & \text { Big data e análise de dados }\end{array}$

Fraco pós-venda

Sistemas de serviços de produtos digitais

Fraco pós-venda

Big data e análise de dados

Problemas de proteção à

Sistemas de serviços e de produtos digitais

propriedade intelectual

Cibersegurança

Big data e análise de dados

Fonte: Elaborada pelos autores.

Para desenvolver a descentralização dos processos, foram propostas tecnologias que auxiliam na gestão de forma mais atual e abrangente. Já, para que o modelo de negócios se adapte as oscilações de mercado, é necessário o desenvolvimento de tecnologias que flexibilizem a produção sem perder a produtividade e eficiência, utilizando para isso intensa coleta de dados. Com relação ao pós-venda, obter dados e informações e utilizá-los de uma forma eficiente e efetiva pode ser uma tarefa facilitada pelos sistemas de produtos digitais e Big Data. Por fim, a segurança digital passa a ocupar papel vital para que os dados coletados e disseminados permaneçam protegidos.

\section{Discussão}

Para facilitar o entendimento das relações da Indústria 4.0 com a pequena e média indústria brasileira, foi desenvolvido um framework (Figura 2) que indica as limitações e caminhos para implementação de todos os conceitos e tecnologias associadas a indústria 4.0. Toda estrutura tem como 
base os dados obtidos com a pesquisa realizada, comparando essas informações com a literatura já citada.

Figura 2

Framework de transição

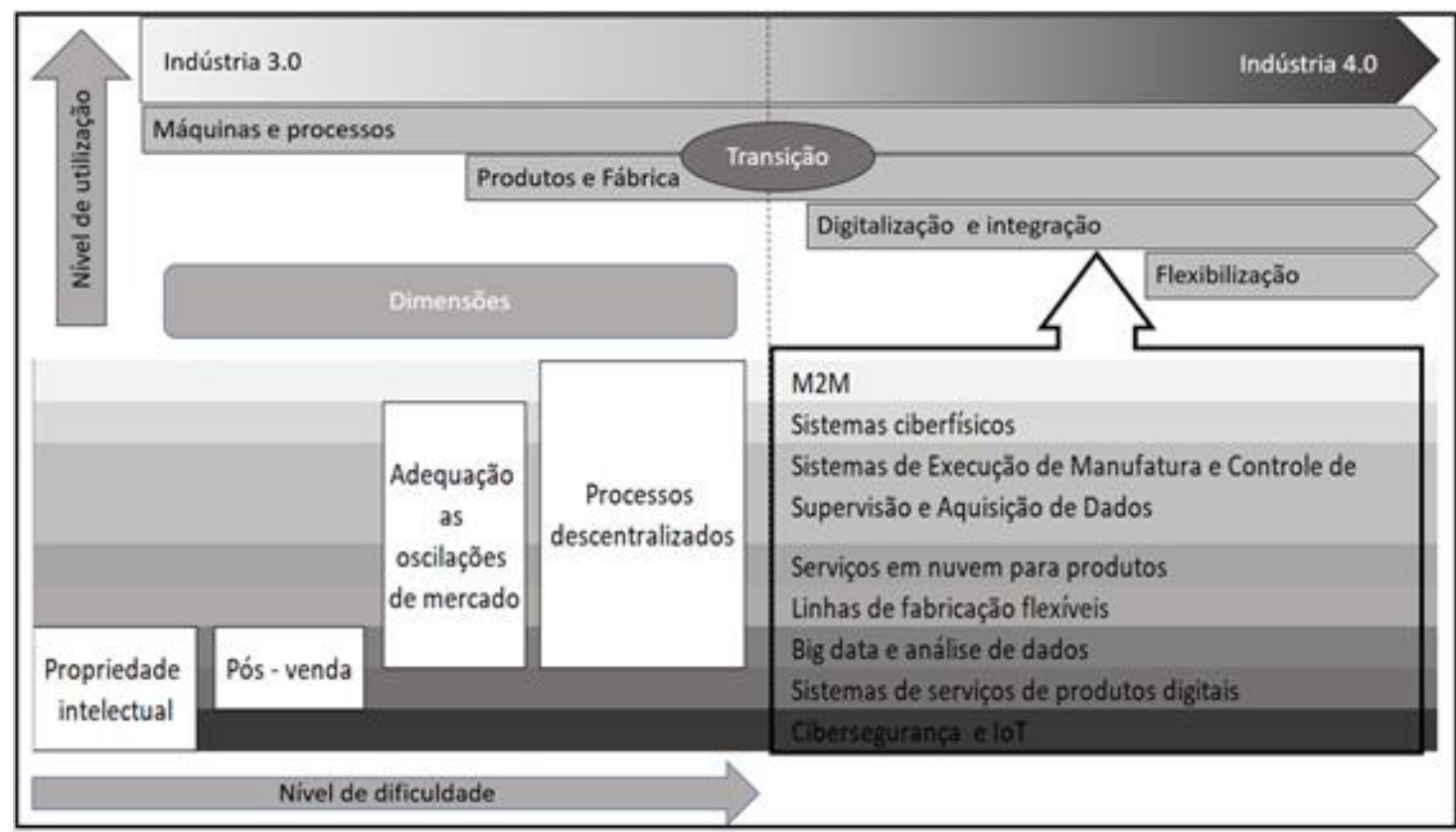

Fonte: Elaborado pelos autores.

$\mathrm{Na}$ parte superior da imagem, encontra-se uma graduação que representa a direção do desenvolvimento partindo da Indústria 3.0 para a 4.0, que o envolve o desenvolvimento industrial do país ao longo dos últimos anos. A classificação feita em base da Indústria 3.0 refere-se à automação clássica e o nível de prontidão tecnológica necessário relacionado com as dificuldades que permeiam essa transição. Nesse sentido, o relatório da CNI (2016) traz importantes resultados ao avaliar o potencial de diferentes tecnologias habilitadoras nesse contexto. Este ponto de partida foi escolhido, pois, segundo as respostas da survey, as tecnologias da terceira revolução industrial consideradas base para o setor metalmecânico já são amplamente utilizadas pelas PMEs. Reynolds e Uygun (2018) afirmam que tecnologias como CAD \CAM são requisitos para PMEs prestarem serviço as grandes empresas em contexto de países desenvolvidos. Partindo deste pressuposto, a primeira das quatro barras abaixo da escala de desenvolvimento, intitulada "Máquinas e processos", corresponde as essas tecnologias que iniciaram na terceira revolução, mas são utilizadas até hoje como ferramentas que digitalizam a operação ampliando a gama de possibilidades para a manufatura. A segunda barra (Produtos e Fábrica) representa tecnologias relacionadas aos produtos, como a customização, por exemplo, e relacionadas a fábrica, como sistema de gestão e simulação para previsão de demanda. Estas áreas também 
representam um bom grau de utilização no setor metalmecânico, mas em menor escala e por este motivo começando depois da primeira barra. A próxima barra (Digitalização e integração) está limitada por uma linha tracejada que representa a fase de transição de 3.0 para 4.0, visto que a transformação 4.0 está mudando as regras de concorrência e os modelos de negócios das empresas sendo totalmente reformuladas pelos conceitos de IoT, CPS e de digitalização (Wang et al., 2015). Para ultrapassar essa barreira, é necessário não só investimento financeiro, mas também mudanças na cultura organizacional, relacionamento com o cliente e alterações nos processos de fabricação (Frank et al., 2019a). Antes de entrar na última barra (Flexibilização) que contempla tecnologias de flexibilização, como robôs autônomos e manufatura aditiva, é necessário que as tecnologias da terceira barra estejam em pleno funcionamento para que o sistema possa ser alimentado de informações, assim, sendo possível investir na quarta barra. Um robô não pode executar uma tarefa sem ter os dados necessários para ser útil a um sistema de produção.

O trabalho de Frank et al. (2019b) vai ao encontro dos achados de transições entre tecnologias 3.0 e 4.0 a partir da proposição de um framework do grau de complexidade para a implementação de tecnologias 4.0. A metade superior o framework está organizado no sentido top-down das tecnologias mais utilizadas para as menos usadas, e concomitantemente na ordem da evolução tecnológica da indústria (Kagermann, 2013). Na parte inferior do framework, ao lado esquerdo estão descritos os problemas e principais dificuldades relacionados às PMEs. Os problemas relacionados ao modelo de negócios estão do lado da 3a revolução industrial por serem problemas já existentes na indústria. No lado direito, estão as tecnologias 4.0 que vieram para ajudar a solucionar esses problemas de maneira integrada. Complementarmente, o tamanho dos quadros dos problemas raiz no modelo de negócios indica quais tecnologias 4.0 na parte direita do framework podem ajudar a resolver tais problemas.

A questão que apresentou maior dificuldade pelas empresas entrevistadas foi "processos descentralizados", definido como de baixo desenvolvimento em 68\% dos casos. A mesma questão, também representa a de maior potencial de melhoria pela intervenção de novas tecnologias, podendo ser desenvolvida a partir da digitalização e integração de processos (Kagermann, 2013, Frank et al., 2019a). Para solucionar problemas relacionados a processos descentralizados, sistemas ciberfísicos podem monitorar e controlar equipamentos, transportadoras e produtos através do gerenciamento de dados, via Big Data e cloud, para atualizar os modelos virtuais dos sistemas de execução de manufatura físicos (Wang et al., 2015). Essa gestão de dados facilita a tomada de decisão em toda cadeia e da mesma forma, tornando a fábrica mais flexível, e com troca de informações direta entre máquinas (M2M), as interferências humanas se restringem as áreas que agregam mais valor. Com relação as oscilações de mercado, sistemas ciberfísicos, utilizando Big Data para coleta de informações e os serviços em nuvem para armazenar os dados, pode criar um sistema para identificar as necessidades dos clientes e assim se adequar as demandas do mercado. Além de promover uma análise remota dos dados para que se 
consiga alcançar os objetivos industriais. Para isso, também é importante uma fábrica flexível que permite a troca de operações e processos para se adequar continuamente (Wang et al., 2015). Para melhorar o pós-venda, é necessário ter as informações e histórico de transações bem armazenas por meio de Big Data e desenvolver serviços e produtos digitais que se comuniquem melhor com o cliente. Através de canais digitais (plataformas) e produtos inteligentes que integram a empresa com os clientes, permitindo assim, uma entrega de maior valor (Kiel et al., 2016; Porter \& Heppelmann, [s.d.]) (Kiel et al., 2016; Porter e Heppelmann, 2014). 21 Para propriedade intelectual, o principal é ter um bom sistema de cibersegurança e loT que protegem os dados utilizados pelas outras tecnologias, bem como identificam documentações necessárias, tributos e normas. As questões de privacidade e segurança de dados precisam ser consideradas no desenvolvimento de modelos de negócios sustentáveis baseados em dados da Indústria 4.0 (Luthra \& Mangla, 2018). Assim, o uso de Big Data Analytics é fundamental no modelo de negócios para saber organizar e separar dados úteis dos inúteis para saber quais informações devem ser protegidas através de criptografias e algoritmos de proteção (Jeschke et al., 2016). Desta forma, a utilização destas tecnologias impulsionaria as PMEs prestadoras de serviço de grandes corporações em direção a Indústria 4.0, melhorando as relações de mercado, otimizando processos, desenvolvendo novos clientes e fornecedores, aumentando margens de lucro e melhorando o sistema fabril como um todo. Para tanto, é necessário que as empresas entendam que o caminho para Indústria 4.0 passa pelas tecnologias mais simples, acessíveis e intangíveis, para depois de implementadas partir para outras mais caras e que auxiliam na flexibilização de processos como robôs autônomos e manufatura aditiva.

\section{Conclusão}

Com base em uma pesquisa realizada com empresas de manufatura, prestadoras de serviços para grandes empresas, este artigo analisou a utilização de tecnologias voltadas à Indústria 4.0 em PMEs brasileiras do setor metalmecânico. A análise também abordou aspectos do modelo de negócios que as empresas apontam como de maior dificuldade para aplicação no dia a dia, relacionando esses desafios com tecnologias para auxiliar no desenvolvimento e fazer a transição dos processos fabris para a Indústria 4.0.

Os resultados mostraram que existe uma divisão de quatro macro etapas para atingir a totalidade dos conceitos 4.0. A primeira refere-se a equipamentos digitais largamente utilizados na indústria e atualmente necessários para atender os grandes mercados. Já a segunda é focada em conceitos de processos e produtos que servem como entrada para conceitos mais avançados. Partindo desse cenário, a transição para a Indústria 4.0 é estabelecida por meio do desenvolvimento de tecnologias de digitalização, integração das fábricas e gestão de dados. Por fim, há ainda uma macro 
etapa em que se encontram tecnologias como robôs autônomos e manufatura aditiva - aqui, existe uma dependência direta das tecnologias do terceiro grupo para sua efetivação. O cruzamento de dados coletados com os conceitos possibilitou a identificação das limitações dos modelos de negócios das empresas e a sugestão de soluções ligadas principalmente à terceira macro etapa. Dessa forma, tomadores de decisão podem usar o modelo para verificar quais são as próximas etapas do desenvolvimento tecnológico que eles podem implementar.

Essa abordagem metodológica mostrou-se bastante satisfatória, visto que a interpretação dos dados evidenciou a divisão entre a indústria tradicional e a 4.0 no mesmo ponto em que as tecnologias 4.0 mais acessíveis poderiam tornar-se ferramentas para transpor as dificuldades dos negócios. Teoricamente, o artigo contribui na interface de diversos pontos interessantes da literatura: desenvolvimento industrial, Indústria 4.0, pequenas e médias empresas e modelos de negócios. Dessa forma, pesquisadores podem usar o framework como ponto de partida para alguns estudos que envolvam as interfaces. Uma das limitações do artigo é a análise de somente um setor da indústria. Para que diversos tomadores de decisão possam utilizar o estudo, é fundamental, para pesquisas futuras, a aplicação do estudo em outros ramos industriais com intuito de perceber padrões na indústria manufatureira.

\section{Referências}

Al-Debi, M. M., El-Haddadeh, R., \& Avison, D. (2008). Defining the business model in the new world of digital business. AMCIS 2008 proceedings, 300.

Amato Neto, J. (2009). Gestão de sistemas locais de produção e inovação (clusters/APLs): Um modelo de referência. São Paulo: Atlas, 178.

Amit, R., \& Zott, C. (2001). Value creation in E-business. Strategic Management Journal, 22(6-7), 493520. https://doi.org/10.1002/smj.187

Balletti, C., Ballarin, M., \& Guerra, F. (2017). 3D printing: State of the art and future perspectives. Journal of Cultural Heritage, 26, 172-182. https://doi.org/10.1016/j.culher.2017.02.010

Bartodziej, C. J. (2017a). Technologies and functions of the concept Industry 4.0. In The Concept Industry 4.0 (p. 51-78). Springer.

Bartodziej, C. J. (2017b). The concept industry 4.0. In The concept industry 4.0 (p. 27-50). Springer.

Basso, D., Neto, B. S., \& Stoffel, J. (2005). Concentração e especialização em setores industriais na região Noroeste Colonial do Rio Grande do Sul. Indicadores Econômicos FEE, 33(3), 163-174.

Becker, J., Knackstedt, R., \& Pöppelbuß, J. (2009). Developing Maturity Models for IT Management: A Procedure Model and its Application. Business \& Information Systems Engineering, 1(3), 213222. https://doi.org/10.1007/s12599-009-0044-5 
Benitez, G. B., Ayala, N. F., \& Frank, A. G. (2020). Industry 4.0 innovation ecosystems: An evolutionary perspective on value cocreation. International Journal of Production Economics, 107735.

Berger, R. (2014). INDUSTRY 4.0-The new industrial revolution/ Maschinenbau/ Engineered Products/High Tech/Branchenexpertise/ Expertise/ Roland Berger.

Bharadwaj, A., El Sawy, O. A., Pavlou, P. A., \& Venkatraman, N. (2013). Digital business strategy: Toward a next generation of insights. MIS quarterly, 471-482.

Brettel, M., Friederichsen, N., Keller, M., \& Rosenberg, M. (2014). How virtualization, decentralization and network building change the manufacturing landscape: An Industry 4.0 Perspective. International journal of mechanical, industrial science and engineering, 8(1), 37-44.

Castelo-Branco, I., Cruz-Jesus, F., \& Oliveira, T. (2019). Assessing Industry 4.0 readiness in manufacturing: Evidence for the European Union. Computers in Industry, 107, 22-32.

Chesbrough, H. (2010). Business model innovation: Opportunities and barriers. Long range planning, 43(2-3), 354-363.

CNI, C. (2016). Indústria 4.0: Novo Desafio para a indústria Brasileira. Indicadores CNI, 17, 13.

Dalenogare, L. S., Benitez, G. B., Ayala, N. F., \& Frank, A. G. (2018). The expected contribution of Industry 4.0 technologies for industrial performance. International Journal of Production Economics, 204, 383-394.

D’aveni, R. A. (2013). 3-D printing will change the world. Harvard business review, 91(3), 34-35.

Doce, L. C., \& de Oliveira Gomes, P. F. (2018). AVALIAÇÃO DO NIVEL DE MATURIDADE DE UMA INDÚSTRIA METAL MECANICA DO NOROESTE DO PARANA COM BASE NOS CONCEITOS DA INDÚSTRIA 4.0. Trabalhos de Conclusão de Curso do DEP, 13(1).

Dorion, E. C. H., Guimarães, J. C. F., Severo, E. A., Reis, Z. C., \& Olea, P. M. (2014). Innovation and production management through a just in sequence strategy in a multinational Brazilian Metal-mechanic Industry. 2014 IEEE International Conference on Management of Innovation and Technology, 54-60. https://doi.org/10.1109/ICMIT.2014.6942400

Fahmideh, M., \& Zowghi, D. (2020). An exploration of loT platform development. Information Systems, $87,101409$.

Fan, J., Yu, S., Chu, J., Chen, D., Yu, M., Wu, T., Chen, J., Cheng, F., \& Zhao, C. (2019). Research on multi-objective decision-making under cloud platform based on quality function deployment and uncertain linguistic variables. Advanced Engineering Informatics, 42, 100932.

Frank, Alejandro G., Mendes, G. H. S., Ayala, N. F., \& Ghezzi, A. (2019a). Servitization and Industry 4.0 convergence in the digital transformation of product firms: A business model innovation perspective. Technological Forecasting and Social Change, 141, 341-351. https://doi.org/10.1016/j.techfore.2019.01.014

Frank, Alejandro Germán, Cortimiglia, M. N., Ribeiro, J. L. D., \& de Oliveira, L. S. (2016). The effect of innovation activities on innovation outputs in the Brazilian industry: Market-orientation vs. technology-acquisition strategies. Research Policy, 45(3), 577-592. 
Frank, Alejandro Germán, Dalenogare, L. S., \& Ayala, N. F. (2019b). Industry 4.0 technologies: Implementation patterns in manufacturing companies. International Journal of Production Economics, 210, 15-26.

Gilchrist, A. (2016). Industry 4.0: The industrial internet of things. Springer.

Goerzig, D., \& Bauernhansl, T. (2018). Enterprise Architectures for the Digital Transformation in Small and Medium-sized Enterprises. Procedia CIRP, 67, 540-545.

https://doi.org/10.1016/j.procir.2017.12.257

Guan, J. C., Mok, C. K., Yam, R. C. M., Chin, K. S., \& Pun, K. F. (2006). Technology transfer and innovation performance: Evidence from Chinese firms. Technological Forecasting and Social Change, 73(6), 666-678. https://doi.org/10.1016/j.techfore.2005.05.009

Hall, B. H., \& Maffioli, A. (2008). Evaluating the impact of technology development funds in emerging economies: Evidence from Latin America. The European Journal of Development Research, 20(2), 172-198. https://doi.org/10.1080/09578810802060819

Hermann, M., Pentek, T., \& Otto, B. (2016). Design Principles for Industrie 4.0 Scenarios. 2016 49th Hawaii International Conference on System Sciences (HICSS), 3928-3937. https://doi.org/10.1109/HICSS.2016.488

Ibarra, D., Ganzarain, J., \& Igartua, J. I. (2018). Business model innovation through Industry 4.0: A review. Procedia Manufacturing, 22, 4-10. https://doi.org/10.1016/j.promfg.2018.03.002

Issa, A., Hatiboglu, B., Bildstein, A., \& Bauernhansl, T. (2018). Industrie 4.0 roadmap: Framework for digital transformation based on the concepts of capability maturity and alignment. Procedia CIRP, 72, 973-978. https://doi.org/10.1016/j.procir.2018.03.151

Jeschke, S., Brecher, C., Meisen, T., Özdemir, D., \& Eschert, T. (2017). Industrial Internet of Things and Cyber Manufacturing Systems. In S. Jeschke, C. Brecher, H. Song, \& D. B. Rawat (Orgs.), Industrial Internet of Things: Cybermanufacturing Systems (p. 3-19). Springer International Publishing. https://doi.org/10.1007/978-3-319-42559-7_1

Kagermann, H., Helbig, J., Hellinger, A., \& Wahlster, W. (2013). Recommendations for implementing the strategic initiative INDUSTRIE 4.0: Securing the future of German manufacturing industry; final report of the Industrie 4.0 Working Group. Forschungsunion.

Kahle, J. H., Marcon, É., Ghezzi, A., \& Frank, A. G. (2020). Smart Products value creation in SMEs innovation ecosystems. Technological Forecasting and Social Change, 156, 120024.

Kaminski, P. C., de Oliveira, A. C., \& Lopes, T. M. (2008). Knowledge transfer in product development processes: A case study in small and medium enterprises (SMEs) of the metal-mechanic sector from São Paulo, Brazil. Technovation, 28(1), 29-36. https://doi.org/10.1016/j.technovation.2007.07.001

Kiel, D., Gasse, L., Arnold, C., Collisi, M., \& Voigt, K.-I. (2016). THE IMPACT OF THE INDUSTRIAL INTERNET OF THINGS ON ESTABLISHED BUSINESS MODELS. Conference Proceedings, 24.

Kumar, N., \& Siddharthan, N. S. (2013). Technology, market structure and internationalization: Issues and policies for developing countries. Routledge. 
Leite, R., Amorim, M., Rodrigues, M., \& Oliveira Neto, G. (2019). Overcoming Barriers for Adopting Cleaner Production: A Case Study in Brazilian Small Metal-Mechanic Companies. Sustainability, 11(17), 4808. https://doi.org/10.3390/su11174808

Li, L. (2018). China's manufacturing locus in 2025: With a comparison of "Made-in-China 2025" and "Industry 4.0". Technological Forecasting and Social Change, 135, 66-74.

Lu, H.-P., \& Weng, C.-I. (2018). Smart manufacturing technology, market maturity analysis and technology roadmap in the computer and electronic product manufacturing industry. Technological Forecasting and Social Change, 133, 85-94. https://doi.org/10.1016/j.techfore.2018.03.005

Luthra, S., \& Mangla, S. K. (2018). Evaluating challenges to Industry 4.0 initiatives for supply chain sustainability in emerging economies. Process Safety and Environmental Protection, 117, 168179. https://doi.org/10.1016/j.psep.2018.04.018

Nick, G., Szaller, Á., Bergmann, J., \& Várged \Ho, T. (2019). Industry 4.0 readiness in Hungary: Model, and the first results in connection to data application. IFAC-PapersOnLine, 52(13), 289-294.

Osterwalder, A., \& Pigneur, Y. (2010). Business model generation: A handbook for visionaries, game changers, and challengers. John Wiley \& Sons.

Pacchini, A. P. T., Lucato, W. C., Facchini, F., \& Mummolo, G. (2019). The degree of readiness for the implementation of Industry 4.0. Computers in Industry, 113, 103125.

Park, N., \& Kim, M. (2014). Implementation of load management application system using smart grid privacy policy in energy management service environment. Cluster Computing, 17(3), 653664.

Pintec, I. B. G. E. (2017). Pesquisa de Inovação Tecnológica. IBGE-Coordenação de indústria, Rio de Janeiro.

Pisano, G. P., \& Shih, W. C. (2012). Producing prosperity: Why America needs a manufacturing renaissance. Harvard Business Press.

Podsakoff, P. M., Mackenzie, S. B., \& Podsakoff, N. P. (2012). Sources of method bias in social science research and recommendations on how to control it. Annual review of psychology, 63, 539569.

Porter, M. E., \& Heppelmann, J. E. (2014). How Smart, Connected Products Are Transforming Competition. 23.

Reynolds, E. B., \& Uygun, Y. (2018). Strengthening advanced manufacturing innovation ecosystems: The case of Massachusetts. Technological Forecasting and Social Change, 136, 178-191. https://doi.org/10.1016/j.techfore.2017.06.003

Rifkin, J. (2001). The age of access: The new culture of hypercapitalism. Penguin.

Rong, K., Patton, D., \& Chen, W. (2018). Business models dynamics and business ecosystems in the emerging 3D printing industry. Technological Forecasting and Social Change, 134, 234-245. https://doi.org/10.1016/j.techfore.2018.06.015 
Rüßmann, M., Lorenz, M., Gerbert, P., Waldner, M., Justus, J., Engel, P., \& Harnisch, M. (2015). Industry 4.0: The future of productivity and growth in manufacturing industries. Boston Consulting Group, 9(1), 54-89.

Scheer, A.-W. (2013). Industrie 4.0: Wie sehen Produktionsprozesse im Jahr 2020 aus. IMC AG.

Scheer, A.-W., 1994. Cim: Computer Integrated Manufacturing towards the Factory of the Future. Secaucus. Springer Verlag, New Jersey, U.S.A.

Schumacher, A., Erol, S., \& Sihn, W. (2016). A Maturity Model for Assessing Industry 4.0 Readiness and Maturity of Manufacturing Enterprises. Procedia CIRP, 52, 161-166.

https://doi.org/10.1016/j.procir.2016.07.040

Severo, Eliana Andrea, Dorion, E. C. H., \& Guimarães, J. C. F. D. (2017). Innovation and environmental sustainability: Analysis in Brazilian metal-mechanic industry. International Journal of Innovation and Sustainable Development, 11(2-3), 230-248. https://doi.org/10.1504/IJISD.2017.083286

Severo, Eliana Andréa, Guimarães, J. C. F. de, Dorion, E. C. H., \& Nodari, C. H. (2015). Cleaner production, environmental sustainability and organizational performance: An empirical study in the Brazilian Metal-Mechanic industry. Journal of Cleaner Production, 96, 118-125. https://doi.org/10.1016/j.jclepro.2014.06.027

Simpson, J. A. (1989). The Oxford english dictionary (Vol. 15). Oxford University Press, USA.

Sok, P., \& O'Cass, A. (2011). Achieving superior innovation-based performance outcomes in SMEs through innovation resource-capability complementarity. Industrial Marketing Management, 40(8), 1285-1293. https://doi.org/10.1016/j.indmarman.2011.10.007

Sturgeon, T. J. (2019). Upgrading strategies for the digital economy. Global Strategy Journal.

Tao, F., Qi, Q., Liu, A., \& Kusiak, A. (2018). Data-driven smart manufacturing. Journal of Manufacturing Systems, 48, 157-169.

Telukdarie, A., Buhulaiga, E., Bag, S., Gupta, S., \& Luo, Z. (2018). Industry 4.0 implementation for multinationals. Process Safety and Environmental Protection, 118, 316-329. https://doi.org/10.1016/j.psep.2018.06.030

Wang, L., Törngren, M., \& Onori, M. (2015). Current status and advancement of cyber-physical systems in manufacturing. Journal of Manufacturing Systems, 37, 517-527. https://doi.org/10.1016/j.jmsy.2015.04.008

Wang, S., Wan, J., Li, D., \& Zhang, C. (2016). Implementing smart factory of industrie 4.0: An outlook. International journal of distributed sensor networks, 12(1), 3159805.

Waterhouse, P. Cooper [PWC]. 2016. PWC Mining Survey 2016-Perceptions on risks and opportunities of investing in Peru's mining sector.

Weller, C., Kleer, R., \& Piller, F. T. (2015). Economic implications of 3D printing: Market structure models in light of additive manufacturing revisited. International Journal of Production Economics, 164, 43-56.

Witzel, J. T. (2017). Análise da influência dos recursos do cluster na vantagem competitiva das firmas: Um estudo no setor metalmecânico e automotivo da serra gaúcha.

Xu, L. D., Xu, E. L., \& Li, L. (2018). Industry 4.0: State of the art and future trends. International Journal of Production Research, 56(8), 2941-2962. 